Article

\title{
Long-Acting Paliperidone Parenteral Formulations Based on Polycaprolactone Nanoparticles; The Influence of Stabilizer and Chitosan on In Vitro Release, Protein Adsorption, and Cytotoxicity
}

\author{
Mohammed Elmowafy ${ }^{1,2, *}$, , Nabil K. Alruwaili ${ }^{1}$, Khaled Shalaby ${ }^{1,2}{ }^{2}$ Khalid S. Alharbi ${ }^{3}$, \\ Waleed M. Altowayan ${ }^{4}$, Naveed Ahmad ${ }^{1}$, Ameeduzzafar Zafar ${ }^{1}$ and Mohammed Elkomy ${ }^{1,5}$ \\ 1 Department of Pharmaceutics, College of Pharmacy, Jouf University, Sakakah P.O. Box 2014, Saudi Arabia; \\ nkalruwaili@yahoo.com (N.K.A.); khsalalbym@yahoo.com (K.S.); naveedahmd@yahoo.com (N.A.); \\ Zafar123@yahoo.com (A.Z.); komy1988@yahoo.com (M.E.) \\ 2 Department of Pharmaceutics and Industrial Pharmacy, Faculty of Pharmacy (Boys), Al-Azhar University, \\ 11751 Nasr City, Cairo, Egypt \\ 3 Department of Pharmacology, College of Pharmacy, Jouf University, Sakakah P.O. Box 2014, Saudi Arabia; \\ khalaharbi@yahoo.com \\ 4 Pharmacy Practice Department, College of Pharmacy, Qassim University, Qassim 51452, Saudi Arabia; \\ waleedmalt@hotmail.com \\ 5 Department of Pharmaceutics and Industrial Pharmacy, Faculty of Pharmacy, Beni-Suef University, \\ 62521 Beni-Suef, Egypt \\ * Correspondence: melmowafy@ju.edu.sa or morere_om@outlook.com; Tel.: +966-5-4186-9569
}

Received: 27 December 2019; Accepted: 4 February 2020; Published: 16 February 2020

\begin{abstract}
Long-acting preparations containing the antipsychotic paliperidone for intramuscular injection has drawn considerable attention to achieve harmless long-term treatment. This study aimed to develop paliperidone loaded polycaprolactone (PCL) nanoparticles and investigate the influence of PCL/drug ratio, stabilizer type, and chitosan coating on physicochemical properties, protein adsorption, and cellular toxicity. Results showed that chitosan coating produced enlarged particle sizes, shifted the surface charges from negative into positive and did not influence encapsulation efficiencies. Chitosan coating relatively sustained the drug release especially in pluronic stabilized formulations. Pluronic F127 based formulations exhibited the least protein adsorption $(384.3 \mu \mathrm{g} / \mathrm{mL})$. Chitosan coating of Tween 80 and polyvinyl alcohol stabilized formulations significantly $(p<0.05)$ increased protein adsorption. Cellular viability was concentration-dependent and negatively affected by stabilizers. All formulations did not show cellular death at $1.56 \mu \mathrm{g} / \mathrm{mL}$. Inflammatory responses and oxidative stress were less affected by Tween 80 compared with other stabilizers. Chitosan minimized all aspects of cellular toxicity. Collectively, stabilizer type and chitosan coating play critical roles in developing safe and effective long-acting PCL nanoparticles intended for parenteral drug delivery. The coated formulations containing Tween 80 and Pluronic F127 as stabilizers are warranted a future in vivo study to delineate its safety and efficacy profiles.
\end{abstract}

Keywords: paliperidone; polycaprolactone nanoparticles; controlled release; stabilizer; chitosan coating; cytotoxicity

\section{Introduction}

Paliperidone (PP) is a benzoxazole derivative clinically used in the treatment of psychosis and schizophrenia (Figure 1). The mechanism of action includes dopaminergic, serotonin, adrenergic, 
and histamine receptors' antagonism. It is the major active metabolite of the atypical antipsychotic risperidone after extensive liver metabolism via hydroxylation (PP is 9-hydroxy-risperidone) [1].

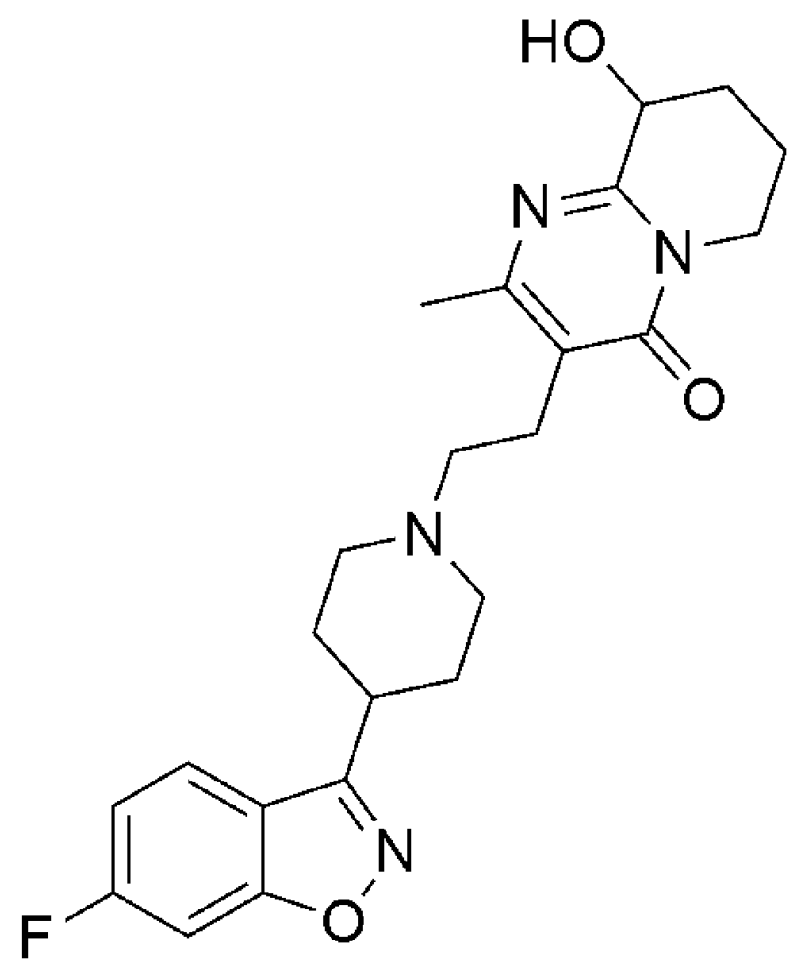

Figure 1. Chemical structure of paliperidone.

Long-acting preparations containing PP for intramuscular injection have drawn considerable attention due to their potential to achieve harmless long term treatment. Commercially available PP palmitate suspension (Invenga ${ }^{\circledR}$ Sustennatm and Xeplion ${ }^{\circledR}$, Janssen Pharmaceutica NV, Beerse, Belgium) is slowly hydrolyzed into active PP producing prolonged antipsychotic effect. This approach is associated with problems such as individual variations in metabolic capacity, sudden failure in drug release into systemic circulation and undesired subclinical inflammatory reaction. Large amounts of crystalline PP have been reported to accumulate in infiltrating macrophages leading to neovascularization after Xeplion ${ }^{\circledR}$ administration [2].

Polymeric devices/drug delivery systems have been proposed to prolong the antipsychotic effect of PP. Wang et al. developed a poly(D,L-lactide-co-glycolide) (PLGA)/dimethyl sulfoxide in situ forming implant system capable of achieving more than a 3-week sustained release and antipsychotic activity in vivo [3]. Recently, Nanaki et al. designed a high surface area mesoporous silica foam incorporated into polymeric microparticles (PLA and PLGA) to enhance PP solubility and prolong its action for 10 to 15 days [4].

Nanoparticle-based delivery systems have got a lot of consideration nowadays due to their unique characteristics which include non-immunogenicity, stability in blood, non-toxicity, non-inflammatory and non-activation of neutrophils [5]. Basically, hydrophobic drugs can be delivered by different nanoparticulate systems such as lipid-based nanoparticles [6], polymeric nanoparticles [7] and lipomer (polymeric lipid hybrid nanoparticles) [8]. Noteworthy, polymeric nanoparticles (PN) possess a wide range of applications in tissue engineering and drug delivery. Especially for biodegradable and biocompatible types, they can improve bioavailability and safety, control the release of encapsulated drugs [9] as well as overcoming physiological barriers [10]. PCL is a semi-crystalline polyester that is FDA approved as a biodegradable and biocompatible polymer. Moreover, PCL nanoparticles can entrap both hydrophilic and lipophilic drugs for controlled release [11], provide a stable system in biological fluids and introduce low toxicity in vitro and in vivo [12]. 
Preparing PN is a complex process that commonly requires formulating with nanoparticle stabilizers. A variety of different stabilizers have been exploited up till now with PCL nanoparticles. These stabilizers include nonionic surfactants such as Tween 80 [13] and polymeric stabilizers such as Pluronic F68 [14], Pluronic F127 [15], and polyvinyl alcohol [16]. Such excipients are expected to influence product stability, release behavior, and safety. One way to modulate the previously mentioned attributes is to coat the PN with hydrophilic polymers. Chitosan is a good candidate owing to its excellent biocompatibility and biodegradability that has been behind its widespread use in the fields of medicine, agriculture, and pharmaceutical, food, and chemicals industry.

Although PCL nanoparticles seem to be one of the most relevant carriers for safe and controlled delivery of drugs, it has never been exploited as a potential carrier for PP. Accordingly, the aim of this work was to formulate PP loaded PCL nanoparticles and investigate the influence of PCL/drug ratio, stabilizer type, and high molecular weight chitosan coating on their physicochemical properties, stability, protein adsorption and cytotoxicity. Our ultimate goal was to develop safe and effective long-acting PCL nanoparticles intended for parenteral delivery of PP.

\section{Materials and Methods}

\subsection{Materials}

PP was purchased from Boss Chemical Industry Co., Ltd. (Jinan, China). PCL (Mw: 70,000-90,000 Da), Pluronic F68, Pluronic F127, polyvinyl alcohol (PVA; Mw: 15,000-20,000) and Tween 80 were purchased from Sigma Aldrich (St. Louis, MO, USA). Chitosan (Mw: 100,000-300,000 Da) was purchased from Acros organics (Geel, Belgium). Bovine serum albumin (BSA) was purchased from Techno Pharmchem (New Delhi, India). The reagents RPMI-1640 medium, 3-(4,5-dimethylthiazol-2-yl)-2,5-diphenyltetrazolium bromide (MTT) and dimethylsulfoxide (DMSO) were purchased from Sigma (St. Louis, MO, USA). Fetal Bovine serum was purchased from Gibco (Loughborough, UK). Other chemicals, reagents, and solvents used were of analytical reagent grade. Highly purified water (Smart2Pure, Thermo Scientific, Stockholm, Sweden) was used for the preparation of all buffer and water-based solutions.

\subsection{Preparation of PP Loaded PCL Nanoparticles}

PP loaded PCL nanoparticles were prepared by the nanoprecipitation method reported by Fessi, et al. [17] with some modifications. During development, we evaluated the ratios of PP: PCL (1:2 and $1: 4 w / w)$ with a fixed ratio of the organic phase to the aqueous phase $(1: 2 v / v)$. The organic phase consisted of acetone/ethyl acetate mixture (1:1 v/v) in which appropriate amounts of PP and PCL were dissolved under mild heating $\left(45^{\circ} \mathrm{C}\right.$ in tightly closed containers) and magnetic stirring (200 rpm) till a clear solution is obtained. To provide the aqueous phase, $0.5 \%$ of different stabilizers (Tween 80 , Pluronic F68, Pluronic F127 and PVA) were dissolved in purified water with the aid of magnetic stirring. Preliminary dispersion in heated water was necessary in the case of PVA. Thereafter, the organic phase was injected dropwise into the aqueous phase under magnetic stirring at $600 \mathrm{rpm}$. Stirring was continued for $4 \mathrm{~h}$ until complete evaporation of the organic solvent. The resultant suspension was filtered $(0.45 \mu \mathrm{m})$ to obtain a suitable nanosized range. The filtrate was subjected to ultracentrifugation $(16,000 \mathrm{rpm})$ at $10^{\circ} \mathrm{C}$ for $30 \mathrm{~min}$ and the supernatant containing unentrapped PP was separated.

For coated formulations, nanoparticles' precipitate was dispersed in $1 \mathrm{~mL} 0.5 \%(w / v)$ chitosan solution, prepared in 1\% acetic acid, and then placed in a shaking incubator (Julabo SW22 GmbH, Seelbach, Germany) at $150 \mathrm{rpm}$ for $4 \mathrm{~h}$ at room temperature. After incubation, the nanoparticles were recovered by ultracentrifugation $\left(16,000 \mathrm{rpm}, 10^{\circ} \mathrm{C}\right.$ for $\left.30 \mathrm{~min}\right)$ and then resuspended in purified water. The resulting supernatant was analyzed to quantify unentrapped PP. The composition of different formulations is outlined in Table 1. 
Table 1. Compositions of different paliperidone (PP)-loaded polycaprolactone (PCL) nanoparticle batches.

\begin{tabular}{cccc}
\hline Code & Surfactant (0.5\%) & Drug/Polymer Ratio & Chitosan Coating \\
\hline F1 & Tween 80 & $1 / 2$ & Uncoated \\
F2 & Tween 80 & $1 / 2$ & Coated \\
F3 & Pluronic F127 & $1 / 2$ & Uncoated \\
F4 & Pluronic F127 & $1 / 2$ & Coated \\
F5 & Pluronic F68 & $1 / 2$ & Uncoated \\
F6 & Pluronic F68 & $1 / 2$ & Coated \\
F7 & PVA & $1 / 2$ & Uncoated \\
F8 & PVA & $1 / 2$ & Coated \\
F9 & Tween 80 & $1 / 4$ & Uncoated \\
F10 & Tween 80 & $1 / 4$ & Coated \\
F11 & Pluronic F127 & $1 / 4$ & Uncoated \\
F12 & Pluronic F127 & $1 / 4$ & Coated \\
F13 & Pluronic F68 & $1 / 4$ & Uncoated \\
F14 & Pluronic F68 & $1 / 4$ & Coated \\
F15 & PVA & $1 / 4$ & Uncoated \\
F16 & PVA & $1 / 4$ & Coated \\
\hline
\end{tabular}

\subsection{Particle size and Zeta Potential}

Particle size (nm), polydispersity index (PI) and zeta potential of PP loaded PN formulations were determined in a Malvern particle size analyzer (Zetasizer Nano ZS, Malvern Instruments, Worcestershire, UK). Formulations were diluted with purified water, in a ratio of 1:10 (v/v) at room temperature before measurement. All measurements were done in triplicates.

\subsection{Production Yield and $p H$}

Production yield was considered as the practical yield of dried nanoparticles (after filtration with $0.45 \mu \mathrm{m}$ filter) recovered from each batch with respect to the total amount of drug and polymers used in each batch. The percentage yield was computed using the following equation:

$$
\text { Yield } \%=\frac{\text { Practical mass of nanoparticles }}{\text { total added amount of PP and PCL }} \times 100
$$

For $\mathrm{pH}$ determination, samples were measured by a $\mathrm{pH}$ meter (HI $2211 \mathrm{pH} / \mathrm{ORP}$ meter, HANNA instruments, Woonsocket, RI, USA) without dilution.

\subsection{PP Encapsulation Efficiency (EE)}

EE\% was determined by measuring entrapped PP in nanoparticles in each batch (direct method). After nanoparticles separation by centrifugation, nanoparticle deposited pellets were dissolved in acetone/ethyl acetate mixture $(1: 1, v / v)$, vortexed (DragonLab, Thermo Scientific, Pudong New Area Shanghai, China) for $5 \mathrm{~min}$ and then analyzed at $323 \mathrm{~nm}$ in a UV-Visible spectrophotometer (Genesys $10 S$ UV-VIS, Thermo Scientific, Pudong New Area Shanghai, China). The calibration curve for the UV assay of PP was constructed using five concentrations ranging from $2.5-25 \mu \mathrm{g} / \mathrm{mL}$. The correlation coefficient $\left(r^{2}\right)$ was about 0.997 . EE\% of PP was calculated according to the following equation:

$$
\mathrm{EE} \%=\frac{\text { Amount of PP analyzed }}{\text { Total added amount of PP }} \times 100
$$

\subsection{In Vitro Release of PP from PN}

In vitro release studies were carried out by a dialyzing/diffusion technique using a screw-capped Spectra/Por ${ }^{\circledR}$ dialyzing tube (Float-A-Lyzer ${ }^{\circledR}$ G2, with Biotech Cellulose Ester Membrane, 8000-10,000 Da MWCO, Sigma Aldrich, St. Louis, MO, USA) tightly closed at both ends. Tubes were previously 
soaked in purified water for $30 \mathrm{~min}$. An aliquot of $1 \mathrm{~mL}$ of PN (equivalent to $10 \mathrm{mg} \mathrm{PP}$ ) was put inside the dialyzing tube which was immersed in tightly covered (to prevent evaporation of release medium) glass beaker containing $400 \mathrm{~mL}$ phosphate-buffered saline (PBS) of $\mathrm{pH}-7.4$ to maintain sink conditions (the solubility of PP in receptor media was about $0.134 \mathrm{mg} / \mathrm{mL}$ ). The whole set was placed on a magnetic stirrer adjusted at $37 \pm 2{ }^{\circ} \mathrm{C}$ and $100 \mathrm{rpm}$. At appropriate time points $(1,2,3,4,6,8,10$, $12,14,16,20,24$, and 28 days), $2 \mathrm{~mL}$ aliquot was withdrawn from the release medium and the same volume of fresh medium was added back to maintain a constant volume. Withdrawn samples were diluted with acetone/ethyl acetate mixture $(1: 1, v / v)$ and the percentage of PP released was determined spectrophotometrically at $323 \mathrm{~nm}$. All samples were measured in triplicate. The cumulative amount of PP released from different formulations after 28 days was statistically compared.

\subsection{Stability}

Shelf stability of the investigated formulations was assessed by storing PN in sealed glass vials at room temperature for 3 months. Investigated parameters included particle size, zeta potential, $\mathrm{pH}$ and $\mathrm{EE} \%$. All measurements were carried out in triplicates.

\subsection{Thermal Study}

Differential scanning calorimetry (DSC) was used to study potential interaction between PP and $\mathrm{PN}$ components through analysis of phase transition temperature. Accurately weighed $5 \mathrm{mg}$ of PP, PCL, stabilizers, physical mixtures and F3 and F4 (as examples of uncoated and coated formulations respectively) were placed in aluminum pans (140 $\mu \mathrm{L}$ capacity), crimped and analyzed by Mettler DSC (DSC3, Mettler Toledo, Switzerland). A standard empty aluminum pan was used as a reference. Thermograms were recorded between $30^{\circ} \mathrm{C}$ and $275^{\circ} \mathrm{C}$ at a scan rate of $10^{\circ} \mathrm{C} / \mathrm{min}$ under nitrogen gas. Data were evaluated with STARe 15.00 software.

\subsection{Fourier Transform-Infrared Spectroscopy}

Interaction between PP and PN components was further verified by Fourier transform infrared spectroscopy (FT-IR). FT-IR analysis was carried out between 4400 and $350 \mathrm{~cm}^{-1}$ in transmission mode for PP, PCL, Pluronic F127, chitosan, F3 and F4 (as examples of uncoated and coated formulations respectively).

\subsection{Morphology}

The shape and appearance of PN were evaluated by Scanning Electron Microscopy (SEM, JOEL, Akishima, Tokyo, Japan). F1, F3 and F7 (as examples of uncoated formulations) and F2, F4, and F8 (as examples of corresponding coated formulations) were diluted with double distilled water (100 folds dilution) and dropped on a flat metallic sample holder and allowed to dry overnight at room ambient temperature. Samples were coated with a gold thin layer using a gold sputter unit. After that, samples were photographed at an acceleration voltage of $10 \mathrm{kv}$.

\subsection{Protein Adsorption}

BSA was used to assess protein adsorption onto nanoparticles' surface by the method described by Kim, et al. [18] with slight modification. One milliliter of BSA solution ( $1 \%$ in PBS; $\mathrm{pH}=7.4)$ was mixed with $0.5 \mathrm{~mL}$ of the investigated formulations and incubated at $37^{\circ} \mathrm{C}$ for $48 \mathrm{~h}$. Non-adsorbed BSA was removed in the supernatant by centrifugation at 15,000 rpm for $15 \mathrm{~min}$. Nanoparticle's pellets were washed thrice with PBS and $250 \mu \mathrm{L}$ of Biuret reagent was added. Biuret reagent/BSA-complex was then determined spectrophotometrically at $540 \mathrm{~nm}$ [19]. A standard curve was previously constructed with known concentrations of BSA. 


\subsection{Cytotoxic Effects}

\subsubsection{Cell Viability}

Formulations were assessed for cytotoxicity using the human lung fibroblast cell line (WI-38; as normal cell model) by MTT assay. The cell line was obtained from ATCC via a holding company for biological products and vaccines (VACSERA, Cairo, Egypt). The cells were cultured in RPMI-1640 medium ( $\mathrm{pH}=7.4$ ) with $10 \%$ fetal bovine serum. Antibiotics added were 100 units $/ \mathrm{mL}$ penicillin and $100 \mu \mathrm{g} / \mathrm{mL}$ streptomycin. The cells were seeded in a 96-well plate at a density of $1.0 \times 10^{4} \mathrm{cells} / \mathrm{well}$ at $37^{\circ} \mathrm{C}$ in a $5 \% \mathrm{CO}_{2}$ incubator for $48 \mathrm{~h}$. To study the effect of concentration, the cells were treated with different concentrations of different formulations after dilution with culture media and then incubated for $48 \mathrm{~h}$. After incubation, $20 \mu \mathrm{L}$ of MTT solution at $5 \mathrm{mg} / \mathrm{mL}$ was added and incubated for $4 \mathrm{~h}$. After that, $100 \mu \mathrm{L}$ of DMSO was added to dissolve the purple formazan formed. The colorimetric assay was performed at an absorbance of $570 \mathrm{~nm}$ using a plate reader (EXL 800, ChroMate-4300, Palm City, FL, USA). This colorimetric assay is based on the conversion of the yellow tetrazolium bromide to a purple formazan derivative by mitochondrial succinate dehydrogenase in viable cells. Experiments were performed using culture media as negative control and stabilizer free formulation (SFF) as a positive control. SFF was prepared by the same above mentioned procedure with sonication (4710 series-Crest Ultrasonic Corp., San Diego, CA, USA) for $10 \mathrm{~min}$ at $50 \mathrm{~W}$ in an ice jacket. Based on the results of cell viability, nanoparticles concentration $50 \mu \mathrm{g} / \mathrm{mL}$ was used for the next two experiments.

\subsubsection{Cytokine Secretions}

Cytokine (tumor necrosis factor-alpha (TNF- $\alpha$ ) and interleukin-6 (IL-6)) secretion following incubation with nanoparticles was assessed using the enzyme-linked immune-sorbent assay technology (ELISA) according to manufacturer standard procedure. Cells were incubated with different formulations for $24 \mathrm{~h}$ and clear supernatants were obtained by centrifugation at $2000 \times g$ for $20 \mathrm{~min}$ at $4{ }^{\circ} \mathrm{C}$ to remove insoluble impurities and cellular debris. The diluted supernatants $(0.1 \mathrm{~mL})$ were added into an anti-cytokine pre-coated 96-well plate which was covered and incubated at $37^{\circ} \mathrm{C}$ for $90 \mathrm{~min}$. Then $0.1 \mathrm{~mL}$ of biotin-conjugated antibody and $0.1 \mathrm{~mL}$ of streptavidin horseradish peroxidase (HRP) were added. Tetramethyl benzidine (TMB) substrates were then added to visualize HPR enzymatic reaction. The density of resultant yellow color was measured at $450 \mathrm{~nm}$ and the concentration $(\mathrm{Pcg} / \mathrm{mL})$ was calculated from reference standard curves. All measurements were done in triplicates.

\subsubsection{Oxidative Stress}

After collecting cells by centrifugation (as mentioned in the above section), cells were homogenized in cold buffer ( $50 \mathrm{mM}$ potassium phosphate, $\mathrm{pH} 7.5,2 \mathrm{mM}$ EDTA). Then the homogenates were centrifuged at $4000 \mathrm{rpm}$ for $15 \mathrm{~min}$ at $4{ }^{\circ} \mathrm{C}$ and supernatants were removed for the assay of malondialdehyde (MDA) and reduced glutathione (GSH). In the case of MDA assay, $0.2 \mathrm{~mL}$ of homogenates were mixed with $1 \mathrm{~mL}$ of thiobarbituric acid (TBA) and left for $30 \mathrm{~min}$ at $95^{\circ} \mathrm{C}$. The resultant pink product was measured at $534 \mathrm{~nm}$. In the case of GSH assay, $0.1 \mathrm{~mL}$ of homogenates were mixed with $0.5 \mathrm{~mL}$ of trichloroacetic acid (TCA) and left for $5 \mathrm{~min}$ at room temperature and then centrifuged at $3000 \mathrm{rpm}$. Aliquots of $0.5 \mathrm{~mL}$ were mixed with $0.1 \mathrm{~mL} 5,5^{\prime}$ (dithiobis (2-nitrobenzoic acid) (DTNB) and left for $10 \mathrm{~min}$. The resultant yellow product was measured at $405 \mathrm{~nm}$. All measurements were done in triplicates.

\subsection{Statistical Analysis}

All results were analyzed by one-way ANOVA and means were compared by Tukey's multiple comparison testing using GraphPad Prism V. 5 software. The inhibitory concentration of $50 \%$ of cells (IC50) was calculated by nonlinear regression utilizing "dose response-inhibition" equations using the same software. A difference with $p<0.05$ was considered to be significant. 


\section{Results and Discussion}

\subsection{Preparation of Formulations}

PP loaded polymeric nanoparticles were prepared by the nanoprecipitation method. This technique involves dissolving PP and PCL in an organic solvent while dissolving a stabilizer in the aqueous phase. By the addition of the organic phase to the aqueous phase, the organic solvent diffuses into the aqueous medium causing the polymer to precipitate into nanosized particles. Simultaneously, the stabilizer self-assembles around the polymeric nanoparticles directing its hydrophobic tail to the hydrophobic polymer core and hydrophilic head group towards the external aqueous environment. Using ethyl acetate as the organic solvent confers a couple of advantages; (1) ethyl acetate is able to dissolve both the drug and the polymer, (2) ethyl acetate can produce relatively small particles owing to its low interfacial tension and high diffusivity into the aqueous phase enabling efficient polymer dispersion [20]. In this study, three factors; chitosan coating, drug/polymer ratio and stabilizer type were studied and their influence on physicochemical characteristics, drug release pattern and cytotoxicity were investigated.

\subsection{Particle Size}

Particle size is considered a versatile factor that influences drug release and in vivo interaction. Smaller particles have a larger surface area and consequent larger burst effect [9], whereas larger particles have a smaller surface area available for water penetration and diffusion and then provide slower drug release patterns [21]. On the other hand, larger particles can interact more prominently with macrophages and get cleared more rapidly.

Table 2 shows the particle size of different formulations. Tween 80, Pluronic F127 and Pluronic F68 produced nanosized particles $(169.1 \pm 5.4 \mathrm{~nm}, 160.8 \pm 3.7 \mathrm{~nm}$, and $152.4 \pm 4.7 \mathrm{~nm}$, respectively) with homogenous and uniform particle size distribution as evidenced by PDI values of $0.116 \pm 0.051$, $0.073 \pm 0.058$ and $0.076 \pm 0.058$, respectively. Using PVA produced significantly $(p<0.05)$ larger particle size $(360.3 \pm 28.5 \mathrm{~nm})$. A possible explanation for this behavior is that PVA could not be homogenously dispersed/dissolved in the cold aqueous phase, which mandated raising the temperature to $45^{\circ} \mathrm{C}$. The increasing temperature might have led to the dissociation of PVA molecules from nanoparticle surface and migration to the bulk medium leaving the nanoparticles uncoated. This, in turn, could cause particle aggregation and consequent sedimentation.

Table 2. Particle size, PDI, zeta potential, yield percent and EE\% of PP loaded nanoparticles ( $n=3, \pm \mathrm{SD})$.

\begin{tabular}{ccccccc}
\hline Code & $\begin{array}{c}\text { Particle Size } \\
(\mathbf{n m})\end{array}$ & PDI & $\begin{array}{c}\text { Zeta Potential } \\
(\mathbf{m} \mathbf{)}\end{array}$ & Yield $\%$ & pH & EE\% \\
\hline F1 & $169.1 \pm 5.4$ & $0.116 \pm 0.051$ & $-9.48 \pm 0.56$ & $68.2 \pm 3.1$ & $6.4 \pm 0.41$ & $58.6 \pm 3.4$ \\
F2 & $246.9 \pm 3.5$ & $0.181 \pm 0.084$ & $31.73 \pm 0.48$ & $62.3 \pm 2.4$ & $5.6 \pm 0.73$ & $58.3 \pm 2.6$ \\
F3 & $160.8 \pm 3.7$ & $0.073 \pm 0.058$ & $-6.67 \pm 1.04$ & $79.4 \pm 5.8$ & $6.2 \pm 0.39$ & $64.8 \pm 5.8$ \\
F4 & $388.6 \pm 10.6$ & $0.351 \pm 0.122$ & $36.71 \pm 1.26$ & $76.9 \pm 1.8$ & $5.7 \pm 0.52$ & $62.3 \pm 7.6$ \\
F5 & $152.4 \pm 4.7$ & $0.076 \pm 0.058$ & $-12.9 \pm 2.83$ & $72.6 \pm 7.3$ & $6.4 \pm 0.40$ & $63.6 \pm 5.8$ \\
F6 & $451.2 \pm 36.3$ & $0.461 \pm 0.073$ & $32.53 \pm 1.20$ & $70.4 \pm 8.1$ & $5.3 \pm 0.17$ & $59.7 \pm 1.5$ \\
F7 & $360.3 \pm 28.5$ & $0.654 \pm 0.156$ & $-4.57 \pm 0.63$ & $38.6 \pm 3.7$ & $6.1 \pm 0.92$ & $51.6 \pm 3.3$ \\
F8 & $415.3 \pm 20.8$ & $0.439 \pm 0.100$ & $31.83 \pm 2.51$ & $32.1 \pm 6.9$ & $5.4 \pm 0.58$ & $51.8 \pm 6.2$ \\
F9 & $166.4 \pm 1.3$ & $0.100 \pm 0.031$ & $-12.91 \pm 0.59$ & $64.7 \pm 5.3$ & $6.6 \pm 0.28$ & $64.2 \pm 1.7$ \\
F10 & $361.2 \pm 17.1$ & $0.345 \pm 0.029$ & $27.37 \pm 0.64$ & $61.9 \pm 1.9$ & $5.7 \pm 0.36$ & $65.1 \pm 2.3$ \\
F11 & $180.5 \pm 4.9$ & $0.405 \pm 0.030$ & $-8.03 \pm 0.587$ & $75.2 \pm 6.3$ & $6.3 \pm 0.12$ & $70.6 \pm 6.8$ \\
F12 & $257.4 \pm 8.3$ & $0.313 \pm 0.069$ & $34.13 \pm 0.25$ & $72.6 \pm 5.9$ & $5.7 \pm 0.73$ & $69.5 \pm 2.9$ \\
F13 & $164.8 \pm 0.5$ & $0.094 \pm 0.040$ & $-15.53 \pm 0.28$ & $66.3 \pm 4.8$ & $6.6 \pm 0.18$ & $66.3 \pm 3.6$ \\
F14 & $453.5 \pm 17.4$ & $0.464 \pm 0.005$ & $37.83 \pm 0.46$ & $61.4 \pm 3.9$ & $5.2 \pm 0.24$ & $65.1 \pm 2.8$ \\
F15 & $368.5 \pm 18.5$ & $0.397 \pm 0.058$ & $-5.41 \pm 0.82$ & $34.5 \pm 7.4$ & $6.3 \pm 0.46$ & $56.4 \pm 9.2$ \\
F16 & $616.4 \pm 30.6$ & $0.468 \pm 0.019$ & $31.37 \pm 0.89$ & $32.8 \pm 2.6$ & $5.5 \pm 0.25$ & $52.3 \pm 8.4$ \\
\hline
\end{tabular}


Drug/polymer ratio did not affect particle size significantly $(p>0.05)$ (Table 2) although previous studies reported that the higher the polymer concentration, the larger the particles produced [22,23]. On the other side, chitosan-coated formulations were associated with significant $(p<0.05)$ particle size increase when compared with the corresponding uncoated ones. This might be attributed to the fact that coating was performed after nanoparticle preparation hence chitosan was located onto particles' surface contributing particle size enlargement.

\subsection{Zeta Potential}

Zeta potential measures the electrokinetic potential of particle surface providing a realistic value of particle surface charge in colloidal systems. Zeta potential can predict stability as the higher the surface charge, the higher the interpaticulate repulsive forces and hence the higher the stability. Table 2 shows zeta potential values of different formulations. In uncoated formulations, particles acquired negative values ranging from $-4.57 \pm 0.63 \mathrm{mV}$ (F7) to $-15.53 \pm 0.28 \mathrm{mV}$ (F13). The negative value is ascribed to ionized polyester's carboxylic terminals [24]. It could also be noticed that the 1:4 drug polymer ratio produced more negative values compared with the 1:2 ratio which is attributed to more exposed carboxyl terminals in the 1:4 ratio. However, the zeta potential of chitosan-coated formulations shifted from negative to positive values owing to the presence of amino groups $\left(-\mathrm{NH} 3^{+}\right)$in chitosan molecules confirming successful particle coating.

\subsection{Yield\%, $p H$, and $E E \%$}

In the determination of the yield \%, a fraction of particles below $450 \mathrm{~nm}$ was separated to investigate the capability of each stabilizer to achieve the particles in the desired size. Table 2 shows the yield \% and EE\% of different formulations. Production Yield was found to be in the range between $79.4 \%$ and $32.1 \%$. Pluronic F127 $(79.4 \% \pm 5.8 \%)$ produced the highest, while PVA produced the lowest yield $(32.1 \% \pm 6.9 \%)$. These values can be explained by the size of particles produced by each of the two stabilizers (Table 2) and confirm the weak surface activity of PVA in PCL polymeric nanoparticles. As expected, the yield percent of chitosan-coated formulations were less than that of the corresponding uncoated ones as chitosan significantly increases particle size.

Unlike yield percentage, $\mathrm{pH}$ was not significantly influenced by the type of stabilizer used (Table 2). However, chitosan-coated formulations were of lower $\mathrm{pH}$ (range: $5.2 \pm 0.24-5.7 \pm 0.73$ ) compared with the corresponding uncoated ones (range: $6.1 \pm 0.92-6.6 \pm 0.28$ ) (Table 2). The presence of acetic acid traces that cause ionization of chitosan amino groups may be responsible for the slight acidic behavior of the chitosan-coated formulations.

Entrapment efficiencies of various formulations were found to be in the range of 51.6 $\pm 3.3-70.6$ $\pm 6.8 \%$. Satisfactory percentages were obtained by all investigated stabilizers except PVA. As PP is a hydrophobic drug $(\log p \sim 1.8)$, it is mostly incorporated into the hydrophobic core of the PCL nanoparticle. Accordingly, the coating of nanoparticles with chitosan did not significantly influence the entrapment of PP.

\subsection{In Vitro PP Release Studies}

The in vitro release pattern of PP from different investigated formulations is depicted in Figure 2. The formulations exhibited biphasic drug release patterns with burst release through the first 4 days followed by sustained release afterward. The fast initial release of PP is probably attributed to untrapped drug bound to the nanoparticle surface. A maximum burst effect was observed in F7 (nearly $45 \%$ of the drug was released) whereas F12 showed minimum initial burst release (nearly $28 \%$ of the drug was released). The sustained release behavior in the later stages is attributed to the slow diffusion of the hydrophobic drug across the polymeric matrix. PCL is characterized by low water permeability [5] and a very slow degradation rate (2-3 years). 
A)

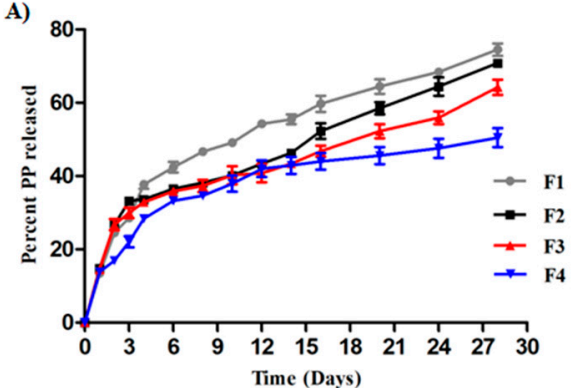

C)

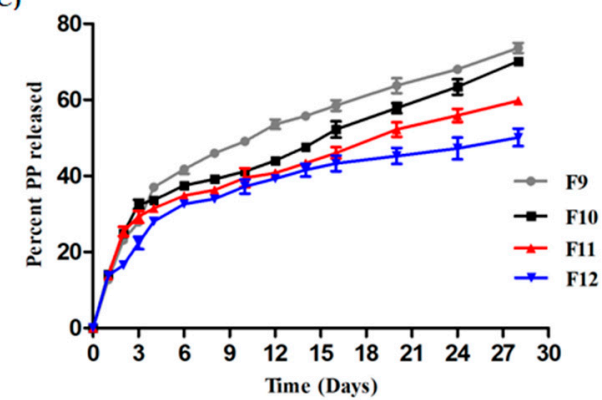

B)

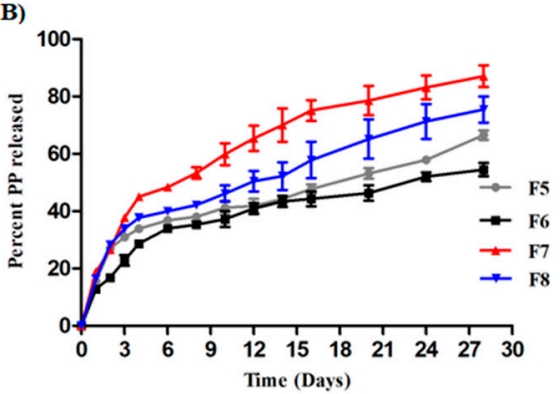

D)

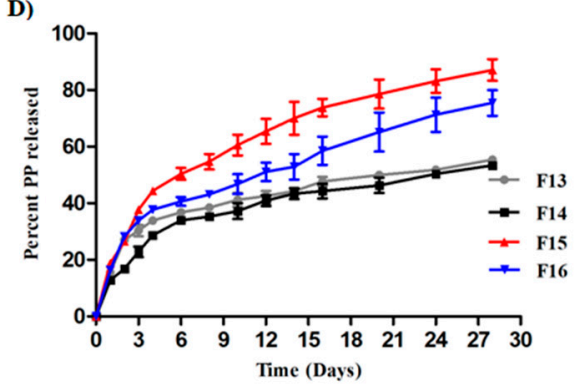

Figure 2. In vitro release profiles of PP from (A) F1-F4, (B) F5-F8, (C) F9-F12, and (D) F13-F16 (mean values $\pm \mathrm{SD}, n=3)$.

Figure 2 shows that chitosan-coated formulations produced slower release in both stages compared with the corresponding uncoated ones. This observation might be ascribed to electrostatic interaction of positively charged chitosan with electronegative oxygen atoms of different stabilizers in slightly acidic media producing a gel with improved mechanical properties and slower drug release rate $[25,26]$. Doubling the amount of polymer added (from 1:2 to 1:4 drug/polymer ratio) reduced PP release, even though this reduction was statistically insignificant $(p>0.05)$.

\subsection{Stability}

The hydrophobic nature of PCL promotes poor stability of nanoparticles when exposed to water. To assess the stability of prepared formulations, they were stored at room temperature for three months and checked for particle size, zeta potential, PI, and EE\% (Table 3). Although the initial results of particle size and PDI showed that F6, F8, F14, and F16 were large (>500 nm) with heterogeneous particle distribution (PDI $>0.3$ ), these formulations did not show a significant difference in particle size and PDI after 3 months. This might be attributed to high positive values of particle surface charge $(>30 \mathrm{mV})$ which in turn promoted particle-particle repulsion and mitigated aggregation. Additionally, zeta potential and encapsulation efficiency of prepared nanoparticles did not change significantly within the three months of stability investigation. 
Table 3. Particle size, PDI, zeta potential, and EE \% of PP loaded nanoparticles within 3 months $(n=3, \pm S D)$.

\begin{tabular}{|c|c|c|c|c|c|c|c|c|c|c|c|c|}
\hline \multirow{2}{*}{ Code } & \multicolumn{4}{|c|}{ 1st Month } & \multicolumn{4}{|c|}{ 2nd Month } & \multicolumn{4}{|c|}{ 3rd Month } \\
\hline & $\begin{array}{c}\text { Particle } \\
\text { Size (nm) }\end{array}$ & PDI & $\begin{array}{c}\text { Zeta } \\
\text { Potential } \\
(\mathrm{mV})\end{array}$ & $\mathrm{EE} \%$ & $\begin{array}{c}\text { Particle } \\
\text { Size (nm) }\end{array}$ & PDI & $\begin{array}{c}\text { Zeta } \\
\text { Potential } \\
(\mathrm{mV})\end{array}$ & $\mathrm{EE} \%$ & $\begin{array}{l}\text { Particle Size } \\
\quad(\mathrm{nm})\end{array}$ & PDI & $\begin{array}{c}\text { Zeta } \\
\text { Potential } \\
(\mathrm{mV})\end{array}$ & EE\% \\
\hline $\mathrm{F} 1$ & $179.3 \pm 2.4$ & $0.12 \pm 0.043$ & $-7.6 \pm 0.41$ & $59.2 \pm 7.3$ & $203.3 \pm 8.3$ & $0.140 \pm 0.090$ & $-8.37 \pm 0.22$ & $57.1 \pm 1.6$ & $213.1 \pm 11.2$ & $0.151 \pm 0.076$ & $-8.87 \pm 0.59$ & $58.3 \pm 3.6$ \\
\hline F2 & $256.7 \pm 6.1$ & $0.192 \pm 0.057$ & $35.39 \pm 1.8$ & $57.1 \pm 3.4$ & $277.7 \pm 9.7$ & $0.163 \pm 0.031$ & $39.60 \pm 2.17$ & $58.1 \pm 6.1$ & $284.3 \pm 9.5$ & $0.176 \pm 0.043$ & $39.63 \pm 1.84$ & $57.6 \pm 3.4$ \\
\hline F3 & $170.4 \pm 5.6$ & $0.09 \pm 0.017$ & $-6.12 \pm 0.63$ & $63.5 \pm 2.6$ & $180.4 \pm 1.8$ & $0.155 \pm 0.026$ & $-5.27 \pm 1.63$ & $61.4 \pm 4.3$ & $182.9 \pm 1.6$ & $0.111 \pm 0.016$ & $-5.91 \pm 0.38$ & $62.2 \pm 1.5$ \\
\hline F4 & $358.5 \pm 9.7$ & $0.376 \pm 0.094$ & $38.43 \pm 4.9$ & $63.8 \pm 4.9$ & $369.5 \pm 7.8$ & $0.303 \pm 0.081$ & $42.37 \pm 2.91$ & $63.1 \pm 8.3$ & $385.7 \pm 6.4$ & $0.344 \pm 0.086$ & $38.74 \pm 1.69$ & $64.2 \pm 1.9$ \\
\hline F5 & $165.3 \pm 4.8$ & $0.093 \pm 0.036$ & $-13.1 \pm 3.4$ & $61.4 \pm 1.9$ & $168.1 \pm 3.2$ & $0.167 \pm 0.055$ & $-14.3 \pm 1.07$ & $62.8 \pm 4.6$ & $175.9 \pm 3.5$ & $0.135 \pm 0.033$ & $-1122 \pm 0.77$ & $61.7 \pm 8.2$ \\
\hline F6 & $571.8 \pm 11.6$ & $0.458 \pm 0.029$ & $30.23 \pm 6.2$ & $57.1 \pm 4.6$ & $586.6 \pm 29.7$ & $0.428 \pm 0.017$ & $27.53 \pm 1.34$ & $56.5 \pm 7.3$ & $587.4 \pm 28.4$ & $0.430 \pm 0.075$ & $32.06 \pm 2.47$ & $54.9 \pm 5.3$ \\
\hline F7 & $369.2 \pm 13.2$ & $0.652 \pm 0.240$ & $-5.12 \pm 0.09$ & $52.3 \pm 1.9$ & $373.4 \pm 31.2$ & $0.627 \pm 0.093$ & $-6.45 \pm 1.19$ & $50.1 \pm 3.1$ & $429.7 \pm 33.2$ & $0.487 \pm 0.078$ & $-5.81 \pm 1.62$ & $51.0 \pm 2.8$ \\
\hline F8 & $525.7 \pm 9.8$ & $0.452 \pm 0.072$ & $30.34 \pm 6.5$ & $51.8 \pm 6.2$ & $559.3 \pm 26.3$ & $0.499 \pm 0.022$ & $29.97 \pm 1.70$ & $52.7 \pm 4.5$ & $564.3 \pm 24.3$ & $0.596 \pm 0.018$ & $36.06 \pm 3.72$ & $50.9 \pm 6.5$ \\
\hline F9 & $179.3 \pm 6.5$ & $0.115 \pm 0.028$ & $-15.22 \pm 1.6$ & $63.9 \pm 4.1$ & $193.9 \pm 8.7$ & $0.118 \pm 0.032$ & $-17.1 \pm 1.48$ & $62.3 \pm 9.3$ & $197.4 \pm 14.1$ & $0.146 \pm 0.063$ & $-14.43 \pm 2.60$ & $61.6 \pm 2.4$ \\
\hline F10 & $370.3 \pm 8.3$ & $0.367 \pm 0.083$ & $27.4 \pm 2.4$ & $62.1 \pm 4.6$ & $379.0 \pm 17.3$ & $0.388 \pm 0.046$ & $27.83 \pm 1.64$ & $61.6 \pm 8.6$ & $382.4 \pm 15.3$ & $0.391 \pm 0.047$ & $27.95 \pm 1.35$ & $61.0 \pm 7.3$ \\
\hline F11 & $230.1 \pm 3.9$ & $0.398 \pm 0.047$ & $-7.3 \pm 0.64$ & $71.3 \pm 2.9$ & $250.1 \pm 10.2$ & $0.416 \pm 0.027$ & $-6.75 \pm 1.02$ & $70.9 \pm 6.8$ & $255.2 \pm 14.6$ & $0.499 \pm 0.0477$ & $7.84 \pm 0.07$ & $70.8 \pm 2.1$ \\
\hline F12 & $269.6 \pm 1.9$ & $0.288 \pm 0.071$ & $36.84 \pm 2.1$ & $68.3 \pm 7.3$ & $300.4 \pm 5.7$ & $0.238 \pm 0.012$ & $39.71 \pm 6.60$ & $67.4 \pm 1.7$ & $314.7 \pm 6.7$ & $0.251 \pm 0.015$ & $35.67 \pm 1.86$ & $66.7 \pm 5.4$ \\
\hline F13 & $181.9 \pm 7.5$ & $0.113 \pm 0.085$ & $-14.6 \pm 0.99$ & $65.1 \pm 5.6$ & $219.3 \pm 2.4$ & $0.230 \pm 0.0473$ & $-13.3 \pm 1.39$ & $66.2 \pm 2.6$ & $222.6 \pm 6.2$ & $0.205 \pm 0.040$ & $-12.29 \pm 2.04$ & $64.3 \pm 2.7$ \\
\hline F14 & $493.1 \pm 10.6$ & $0.415 \pm 0.032$ & $37.3 \pm 4.6$ & $62.9 \pm 1.9$ & $496.1 \pm 13.6$ & $0.409 \pm 0.026$ & $38.70 \pm 1.75$ & $60.1 \pm 6.9$ & $496.3 \pm 22.9$ & $0.422 \pm 0.063$ & $39.67 \pm 1.34$ & $61.3 \pm 8.1$ \\
\hline F15 & $273.8 \pm 2.4$ & $0.393 \pm 0.022$ & $-5.37 \pm 0.17$ & $52.1 \pm 7.3$ & $286.3 \pm 5.1$ & $0.391 \pm 0.024$ & $-5.53 \pm 1.78$ & $53.1 \pm 4.4$ & $297.3 \pm 4.8$ & $0.298 \pm 0.086$ & $-4.71 \pm 0.89$ & $52.6 \pm 6.2$ \\
\hline F16 & $626.4 \pm 13.1$ & $0.455 \pm 0.056$ & $33.46 \pm 3.5$ & $53.5 \pm 1.6$ & $673.3 \pm 38.2$ & $0.454 \pm 0.044$ & $38.37 \pm 5.41$ & $52.2 \pm 5.8$ & $683.7 \pm 36.3$ & $0.395 \pm 0.026$ & $34.92 \pm 2.40$ & $51.8 \pm 3.3$ \\
\hline
\end{tabular}




\subsection{Thermal Analysis}

To describe the crystallinity of PP and PCL individually and after formulation in polymeric nanoparticles, DSC analyses were performed (Figure 3). PP showed a sharp endothermic peak at $185.3^{\circ} \mathrm{C}$ followed by a broad exothermic peak indicating drug decomposition after transition [27]. PCL showed a main endothermic peak at $69.8^{\circ} \mathrm{C}$. F3 exhibited a peak at $58.7^{\circ} \mathrm{C}$. Shifting of PCL peak into lower temperatures in the nanoparticles may be attributed to the presence of particles in the nano-range. However, the vanishing of the PP characteristic peak in the thermogram of nanoparticles suggests the existence of the crystalline drug in an amorphous state of molecular dispersion or solid solution state within the polymeric matrix [28]. In addition, the thermogram of F3 formulation showed a reduction in endothermic peak intensity. This behavior is possibly due to PCL chain disorganization occurring when pure materials are incorporated in Pluronic F127 containing system, leading to lower energy necessary to melt the polymer crystals [29]. Moreover, the presence of both peaks in the physical mixture confirmed the interaction between PP and PCL in nanoparticle formulations. It is noteworthy that F4 (chitosan-coated F3) exhibited the same thermogram of F3 suggesting possible Pluronic chitosan interaction.

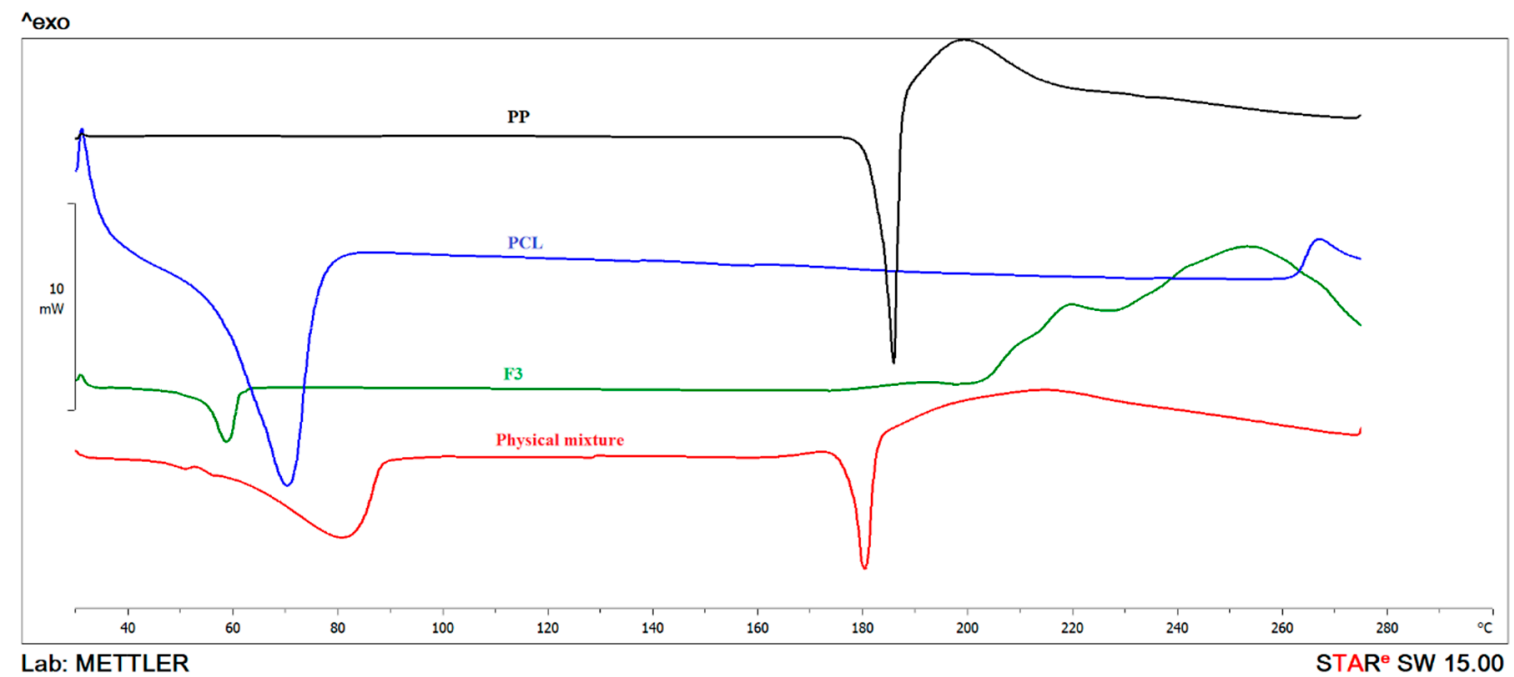

Figure 3. DSC thermograms of; PP, PCL, F3, and physical mixture.

\subsection{FT-IR Analysis}

Interaction (presented as bond formation) of $\mathrm{PP}$ and other polymeric nanoparticle components was further assessed by FT-IR. In addition to pure PP, PCL, Pluronic F127 (PF127) and chitosan, F3 and F4 FT-IR spectra are shown in Figure 4. PP spectrum showed characteristic peaks at $3294.78 \mathrm{~cm}^{-1}$ (represented $-\mathrm{OH}$ stretch), $2934.16 \mathrm{~cm}^{-1}$ (represented $\mathrm{CH}$ stretch), $1627 \mathrm{~cm}^{-1}$ (represented $\mathrm{C}=\mathrm{C}$ stretch), $1535.06 \mathrm{~cm}^{-1}$ (represented $\mathrm{C}=\mathrm{N}$ stretching), and $1131.05 \mathrm{~cm}^{-1}$ (represented C-F stretching) [30]. PCL spectrum exhibited characteristic bands at $3420.13 \mathrm{~cm}^{-1}$ (represented terminal hydroxyl group), $2940.6 \mathrm{~cm}^{-1}$, and $2867.8 \mathrm{~cm}^{-1}$ (represented asymmetric and symmetric aliphatic stretching respectively). In addition, the PCL spectrum showed polyester carbonyl stretching $(C=O)$ absorption peak at $1728.5 \mathrm{~cm}^{-1}$ and stretching vibration bands of $\mathrm{C}-\mathrm{O}-\mathrm{C}$ bonds at $1169.9 \mathrm{~cm}^{-1}$ [31]. Pluronic F127 spectrum showed peaks at $2878.24 \mathrm{~cm}^{-1}$ and $1108.84 \mathrm{~cm}^{-1}$, representing $\mathrm{C}-\mathrm{H}$ and $\mathrm{C}-\mathrm{O}$ stretching, respectively; and an absorption band at $3437.5 \mathrm{~cm}^{-1}$ corresponding to $\mathrm{O}-\mathrm{H}$ group stretching. After matching PP characteristic peaks with F3 peaks it is possible to say that the F3 spectrum is devoid of most PP characteristic peaks indicating successful encapsulation within polymeric nanoparticles. Moreover, the F3 spectrum contained the $\mathrm{C}-\mathrm{O}$ stretching peak $\left(1107.3 \mathrm{~cm}^{-1}\right)$ of Pluronic F127 indicating surface coating by the stabilizer. Chitosan spectrum revealed characteristic bands at $1633.41 \mathrm{~cm}^{-1}$ representing vibration of the carbonyl group of acetylated amide and $1532.6 \mathrm{~cm}^{-1}$ representing stretching of the free 
amino group. The chitosan-coated F3 (F4) spectrum showed absence of Pluronic F127 C-O stretching peak with shifting in amide carbonyl group and amino group of chitosan confirming surface interaction between Pluronic F127 and chitosan.

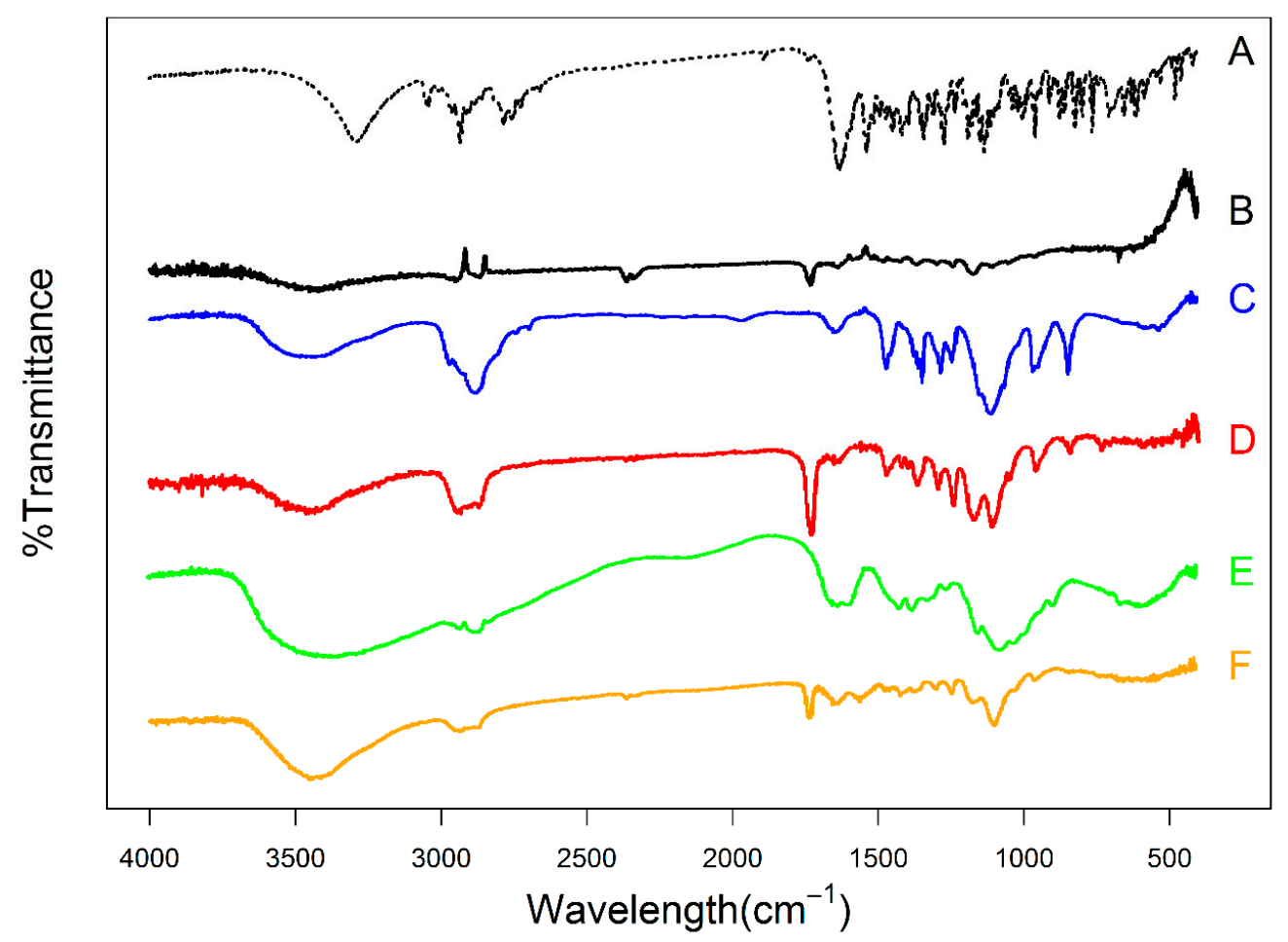

Figure 4. FT-IR spectra of (A); PP, (B); PCL, (C); Pluronic F127, (D); F3, (E); chitosan, and (F); F4.

\subsection{Surface Morphology}

The morphological characteristics of coated and uncoated nanoparticles were observed by SEM (Figure 5A-F). Particles were assessed for surface smoothness, discreteness, shape, and homogeneity. It was clear that the particles were of smooth surface, undetectable aggregation, and spherical shape. Particles with a smooth surface and spherical shape were reported to be of less tissue irritation than irregular and crystalline particles [32]. The particles of coated formulations appeared of a smaller size than that obtained by zeta sizer measurements which might be attributed to a hydrated layer formed on chitosan-coated formulations during measuring particle size by dynamic light scattering [33]. Dynamic light scattering reflects the hydrodynamic diameter, whereas SEM reflects the actual diameter of the dry state. Additionally, the micrographs revealed more pronounced heterogeneity in coated particle distribution compared with the corresponding uncoated particle distribution which was in good agreement with the results obtained from the zeta sizer analysis. 

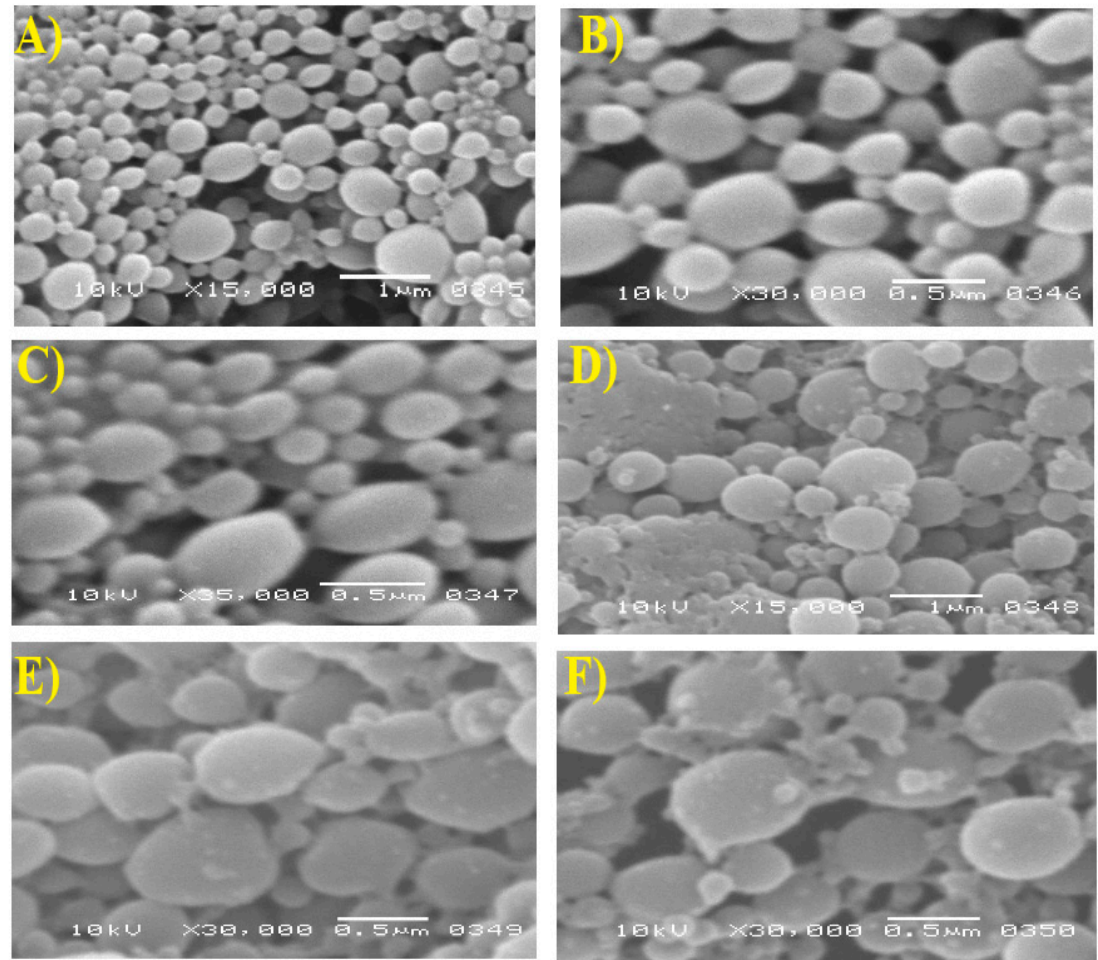

Figure 5. Scanning electron microscope images of (A) F1; (B) F2; (C) F3; (D) F4; (E) F7 and (F) F8.

\subsection{BSA Adsorption}

As prepared nanoparticles are intended for parenteral administration, the amount of BSA adsorbed onto different formulations was determined by the Biuret-protein complex assay (Figure 6A,B). Protein adsorption influences subsequent phagocytosis, membrane transport and circulation half-life [34]. The degree of protein adsorption is influenced by several factors such as electrostatic interaction [35], hydrophobicity [36], surface roughness [37], and hydrogen bonding. Considering stabilizer effect, PVA based formulation (F7) exhibited the greatest BSA adsorption $(450 \pm 6 \mu \mathrm{g} / \mathrm{mL})$ whereas Pluronic F127 based formulation (F3) exhibited the least adsorption $(384.3 \pm 5.5 \mu \mathrm{g} / \mathrm{mL})$ among uncoated formulations. Higher BSA adsorption in the case of PVA stabilized formulations is thought to be due to lower softness of large particles [38] and hence easy protein adsorption [39]. Pluronics are triblock copolymers of polyethylene oxide (PEO)-polypropylene oxide (PPO)-polyethylene oxide (PEO), which were well established of their steric effect [40] and specifically in resisting interaction with serum components [41]. This behavior could partly explain the lower BSA adsorption in pluronic containing formulations when compared with Tween 80 and PVA. Pluronic F127 based formulation adsorbed less BSA than F68. This might be ascribed to the fact that the hydrophilic chain (PEO) responsible for the steric effect of the copolymer is more predominant in the F127 grade. The lower BSA adsorption in the case of Tween 80 based formulation compared with PVA might be related to the prevalence of negative charge on the surface of F1 which could promote repulsive force with carboxylic acid carrying BSA. On the contrary to nanoparticle stabilizers, higher PCL concentration (1:4 drug to polymer ratio; F9-F16) did not produce a significant effect on BSA adsorption when compared to corresponding formulations containing lower PCL concentration (data not shown). 
A)

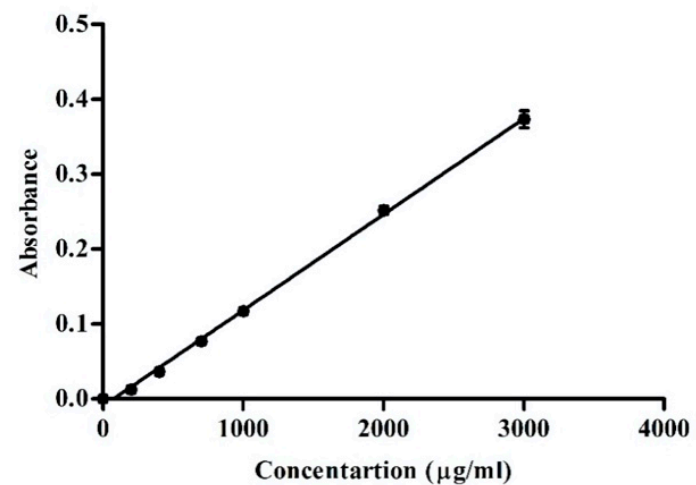

B)

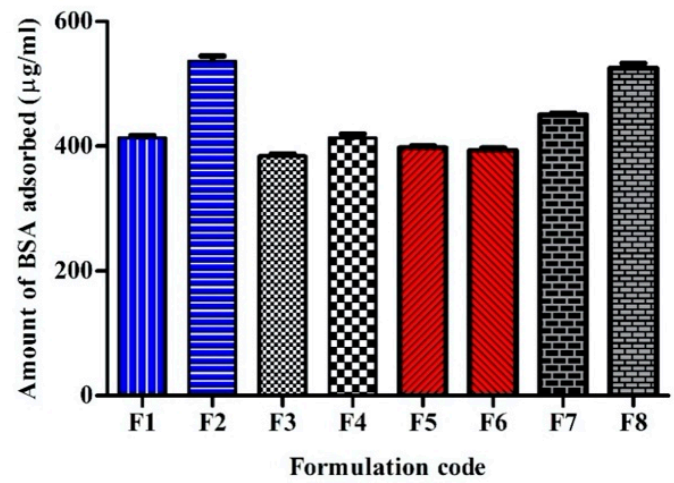

Figure 6. (A) Calibration curve of Biuret-BSA complex and (B) amounts of bovine serum albumin (BSA) adsorbed onto different formulations $(n=3)$.

Chitosan coated formulations displayed variable responses towards BSA adsorption. F2 and F8 showed significant $(p<0.05)$ higher BSA adsorption compared with F1 and F7. This could be attributed to different electrostatic interactions caused by the different $\mathrm{pH}$ values of the formulations. The isoelectric point (the $\mathrm{pH}$ at which molecule is of zero charge) of chitosan is 6.2-6.8 [42]. Below this $\mathrm{pH}$, the amino group of chitosan will be protonated and carry a positive charge. In addition, the isoelectric point of BSA is 4.7-4.9 [43]. Above this $\mathrm{pH}$, the carboxylic group of BSA will be dissociated and carry a negative charge. In the case of $\mathrm{F} 1(\mathrm{pH} 6.4 \pm 0.41)$ and $\mathrm{F} 7(\mathrm{pH} 6.1 \pm 0.92)$, chitosan amino groups are less protonated compared with F2 ( $\mathrm{pH} 5.6 \pm 0.73)$ and F8 ( $\mathrm{pH} 5.4 \pm 0.58)$, thus attract less of BSA dissociated carboxylic groups. Interestingly, chitosan coating of Pluronic stabilized formulations did not produce significant $(p>0.05)$ BSA adsorption which might be ascribed to electrostatic interaction between protonated chitosan and electronegative oxygen atom in the POE part of Pluronic which in turn restricted the interaction of chitosan with BSA.

\subsection{Cell Viability}

The percentage of viable WI-38 cells after $48 \mathrm{~h}$ determined via MTT assay is depicted in Figure 7A-D. The $48 \mathrm{~h}$ period is long enough to check and predict long term cellular toxicity. Results showed that all formulations produced cell toxicity in a concentration-dependent manner. The higher the nanoparticle concentration, the more cytotoxic they were. SFF showed considerable cell viability percentage $(70.6 \pm 2.1 \%$ of cells were viable after incubation with the highest concentration) and higher IC50 $(31.6 \pm 1.7 \mu \mathrm{g})$ which were significantly $(p<0.05)$ higher than that of stabilizer containing formulations. This result confirms the safety of PCL on the molecular level [44] even in high molecular weights. 
A)

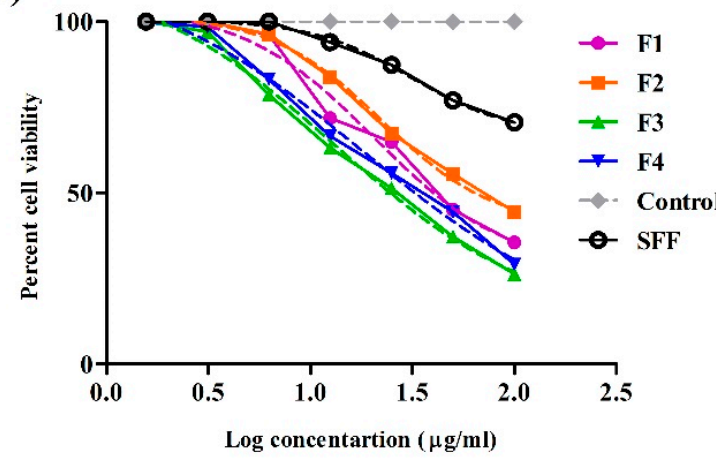

C)

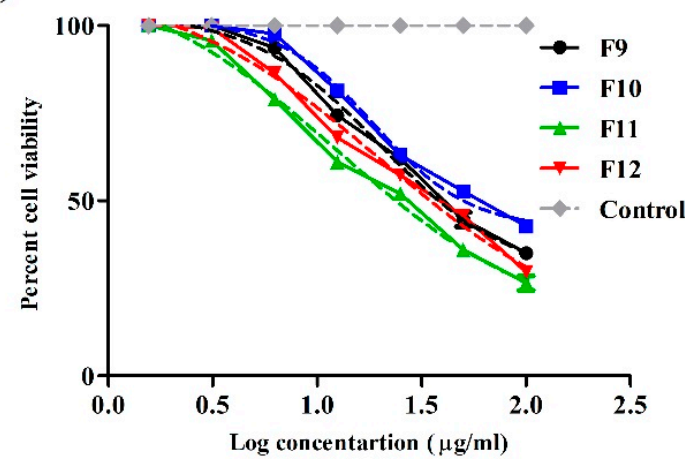

B)

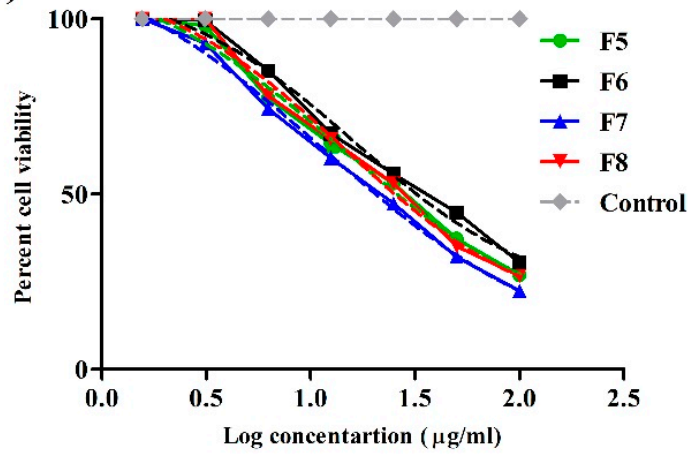

D)

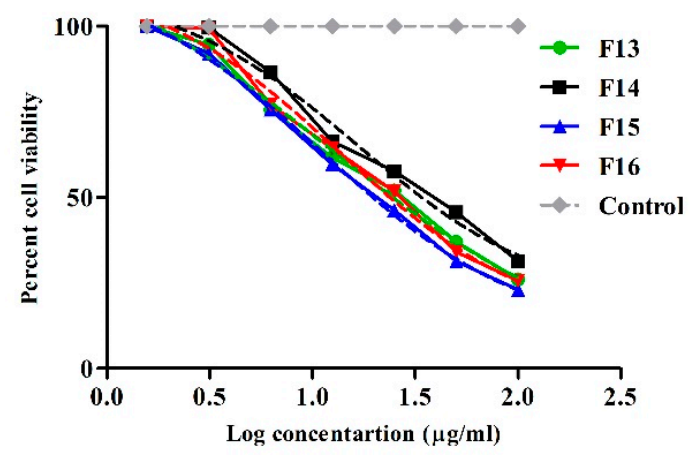

Figure 7. Percentage of cell viability of WI-38 cell line incubated with culture media (control) and different concentrations of stabilizer free formulation (SFF) and all other investigated formulations ((A), for F1-F4; (B), for F5-F8; (C), for F9-F12; (D), for F13-F16) after $48 \mathrm{~h}$ by MTT assay $(n=3)$. Continuous lines represent the actual curves of the original values while dashed lines represent curves after a non-linear fit of data of corresponding colors.

Stabilizer containing formulations in the higher concentration $(100 \mu \mathrm{g} / \mathrm{mL})$ caused the death of approximately $70 \%$ of the viable cells depending on formulation constituents, although all formulations at the lowest concentration $(1.56 \mu \mathrm{g} / \mathrm{mL})$ did not exhibit any cell death. IC50 values of such formulations were also significantly decreased when compared with SFF. IC50 values (Table 4) were $20.65 \pm 0.7 \mu \mathrm{g}$, $13.27 \pm 0.4 \mu \mathrm{g}, 13.91 \pm 0.5 \mu \mathrm{g}, 11.56 \pm 0.08 \mu \mathrm{g}, 20 \pm 1.4 \mu \mathrm{g}, 12.94 \pm 0.7 \mu \mathrm{g}, 11.99 \pm 0.07 \mu \mathrm{g}, 11.27 \pm 0.09 \mu \mathrm{g}$ for F1, F3, F5, F7, F9, F11, F13, and F15 respectively. These findings simply imply that stabilizer concentration represents a crucial factor affecting cellular safety which is in good agreement with the literature data. Grabowski et al. reported that the toxicity of polymeric nanoparticles could be mediated by surface coating with different stabilizers [45]. Abriata et al. [15] showed that Pluronic F127 stabilized PCL nanoparticles did not exhibit any cytotoxic effect on the LLC-MK2 cell line at the highest concentration used $(120 \mu \mathrm{M})$. The investigators used lower molecular weight PCL (14,000 Da) and different cell lines (LLC-MK2 cells), which might explain the different findings relative to our study.

Table 4. IC50 of different PP loaded PCL nanoparticle batches after incubation with WI-38 cells for $48 \mathrm{~h}$.

\begin{tabular}{cccc}
\hline Code & IC50 $(\mu \mathrm{g} \pm \mathrm{SD})$ & Code & IC50 $(\mu \mathrm{g} \pm \mathrm{SD})$ \\
\hline F1 & $20.65 \pm 0.7$ & F9 & $20 \pm 1.4$ \\
F2 & $22.5 \pm 2.8$ & F10 & $18.66 \pm 0.7$ \\
F3 & $13.27 \pm 0.4$ & F11 & $12.94 \pm 0.7$ \\
F4 & $18.37 \pm 1.4$ & F12 & $20.48 \pm 1.3$ \\
F5 & $13.91 \pm 0.5$ & F13 & $11.99 \pm 0.07$ \\
F6 & $16.23 \pm 0.9$ & F14 & $16.68 \pm 0.8$ \\
F7 & $11.56 \pm 0.08$ & F15 & $11.27 \pm 0.09$ \\
F8 & $14.49 \pm 1.1$ & F16 & $13.65 \pm 0.08$ \\
\hline
\end{tabular}


All chitosan-coated formulations exhibited less cytotoxic effect than the corresponding uncoated ones at all concentrations. IC50 values were $22.5 \pm 2.8 \mu \mathrm{g}, 18.37 \pm 1.4 \mu \mathrm{g}, 16.23 \pm 0.9 \mu \mathrm{g}, 14.49 \pm 1.1 \mu \mathrm{g}$, $18.66 \pm 0.7 \mu \mathrm{g}, 20.48 \pm 1.3 \mu \mathrm{g}, 16.68 \pm 0.8 \mu \mathrm{g}, 13.65 \pm 0.08 \mu \mathrm{g}$ for F2, F4, F6, F8, F10, F12, F14, and F16 respectively. Generally, cationic polymers interact with the anionic constituent of glycoprotein (sialic acid) and produce cell damage. However, chitosan was reported to be less toxic than other cationic polymers as polyethyleneimine [46]. Chitosan can mediate cellular damage if present in a charged form. In our study, the formulations were diluted with culture media of $\mathrm{pH} 7.4$, the $\mathrm{pH}$ at which chitosan is mostly uncharged [47] which in turn masked its toxicity.

\subsection{Cytokine Secretions}

The cellular inflammatory response was investigated by the determination of TNF- $\alpha$ and IL- 6 (Figure 8A,B respectively). Although SFF showed a slight release of both TNF- $\alpha$ and IL-6, it still exhibited significantly lower levels than stabilizers containing formulations confirming the crucial role of stabilizers in triggering inflammatory responses. Grabowski et al. suggested that nanoparticles could provoke stabilizer cellular internalization which could not occur if used in a free form [45]. The formulation F1 (stabilized by Tween 80) showed the lowest TNF- $\alpha$ and IL-6 secretions (266 \pm 3.7 and $156.3 \pm 2.8 \mathrm{Pcg} / \mathrm{mL}$ ) among all uncoated formulations. The extent of secretion was ranked as: F7 > F3 > F5 > F1. The results of IL-6 are in good accordance with Schöler et al. who studied the effect of different stabilizers on cytotoxicity and cytokine production of solid lipid nanoparticles [48]. The authors found that Tween 80 produced less IL- 6 than Pluronics. Chitosan coated formulations showed significantly lower TNF- $\alpha$ and IL-6 secretions when compared to the corresponding uncoated formulations confirming the good biocompatibility and minimum cellular interaction of chitosan. Unlike stabilizer and chitosan coating, PCL concentration could not be associated with TNF- $\alpha$ and IL-6 secretions where no statistical significance was observed when the higher polymer drug ratio (4:1) was used.

A)

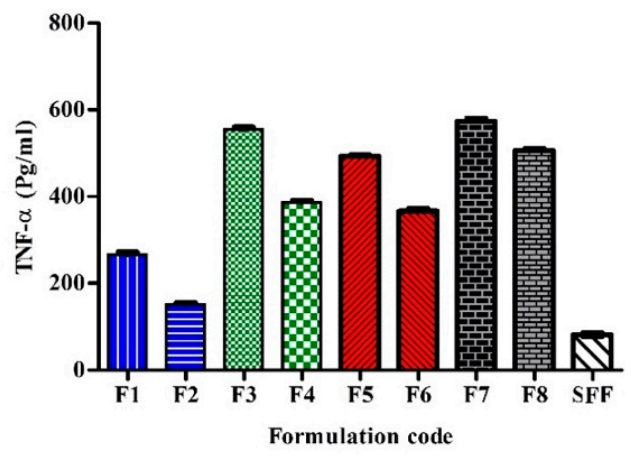

B)

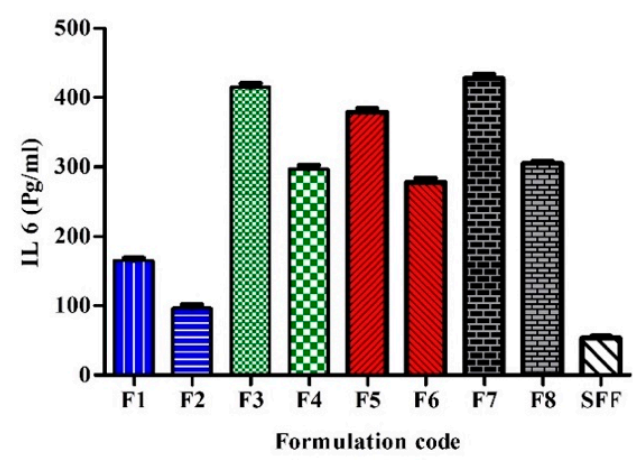

Figure 8. Secretions of (A) TNF- $\alpha$ and (B) IL-6 of SFF and different stabilizers containing formulations after incubation with $50 \mu \mathrm{g} / \mathrm{mL}$ after $24 \mathrm{~h}(n=3)$. 


\subsection{Oxidative Stress}

Oxidative stress was investigated by the determination of MDA and GSH (Figure 9A,B, respectively). MDA is the end product of lipid peroxidation of which high level designates tissue damage and failure of anti-oxidant mechanisms [49]. GSH is the major non-protein thiol in living organisms that can remove free radical species and preserving membrane integrity. Significantly, lower MDA $(0.41 \pm 0.03 \mathrm{mmoL} / \mathrm{L})$ and higher GSH $(0.98 \pm 0.05 \mathrm{mmoL} / \mathrm{L})$ levels were seen in SFF incubated cells when compared to surfactant stabilized formulations, confirming the critical role of surfactants in cell survival. The results of oxidative stress corroborated with previous results of cell viability and inflammatory responses and evidenced the ability of chitosan-coated PCL nanoparticles to minimize stabilizer cytotoxic effects and contribute to their safety index.

A)

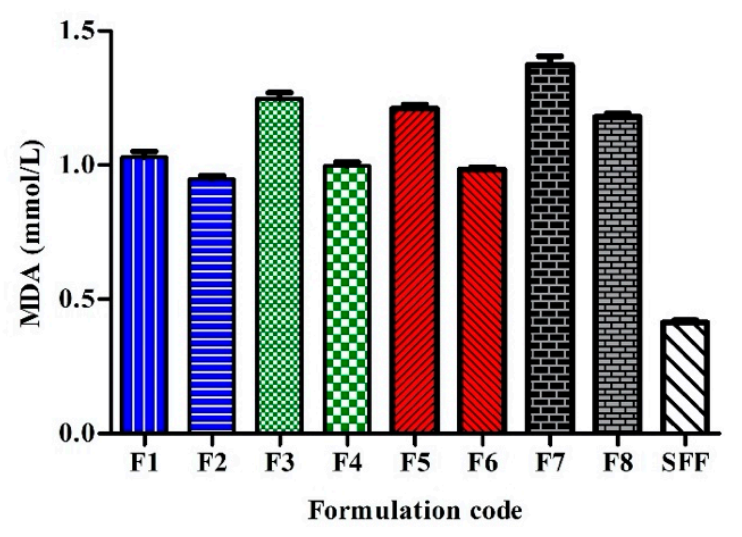

B)

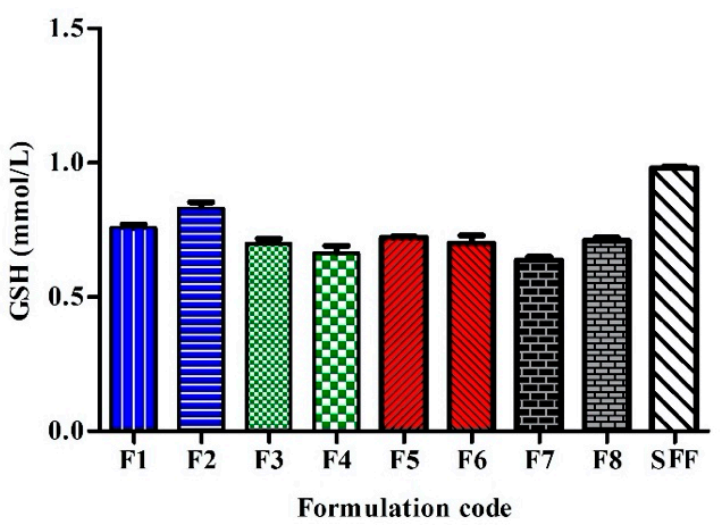

Figure 9. Intracellular production of (A) malondialdehyde (MDA) and (B) reduced glutathione (GSH) after exposure to SFF and different stabilizers containing formulations after incubation with $50 \mu \mathrm{g} / \mathrm{mL}$ after $24 \mathrm{~h}(n=3)$.

\section{Conclusions}

PP loaded PCL nanoparticles can be successfully prepared by the nanoprecipitation technique. Surfactants can produce spherical nanosized particles with low polydispersity index, negative surface charge, and high encapsulation ability. Chitosan coating increases particle size and shifts surface charge to positive values. PP is slowly released from the nanoparticles in a biphasic mode. The highest sustainability is achievable by coating Pluronic stabilized nanoparticles with chitosan. Among tested stabilizers, Pluronic F127 adsorb the least amount of protein and Tween 80 triggers the least influence on cytokine secretions and oxidative stress markers. Cell viability depends on stabilizer concentration rather than the stabilizer type. Chitosan-coating minimizes stabilizer induced cytotoxicity, cytokine 
secretion, and oxidative stress response, although it augments nanoparticle protein adsorption capacity. The effect of chitosan on protein adsorption is neutralized when coupled with Pluronics stabilizer. Our results indicate that stabilizer type/concentration and chitosan coating play critical roles in developing safe and effective long-acting PCL nanoparticles intended for parenteral drug delivery. Based on the analysis provided above, the formulations F2 and F4 (chitosan-coated formulations containing Tween 80 and Pluronic F127 as stabilizers, respectively) are warranted a future in vivo study to delineate its safety and efficacy profiles.

Author Contributions: Conceptualization, N.K.A.; Data curation, M.E. (Mohammed Elmowafy), N.K.A. and M.E. (Mohammed Elkomy); Formal analysis, M.E. (Mohammed Elmowafy); Investigation, K.S.A., N.A. and A.Z.; Methodology, M.E. (Mohammed Elmowafy) and K.S.; Project administration, N.K.A.; Resources, M.E. (Mohammed Elmowafy), N.K.A., K.S. and W.M.A.; Software, K.S.A. and M.E. (Mohammed Elkomy); Supervision, N.K.A.; Visualization, M.E. (Mohammed Elmowafy). All authors have read and agreed to the published version of the manuscript.

Funding: This research was funded by the Deanship of Scientific Research, Jouf University, Aljouf, Saudi Arabia (grant no. 39/311).

Acknowledgments: This work was financially supported by the Deanship of Scientific Research, Jouf University, Aljouf, Saudi Arabia (grant no. 39/311).

Conflicts of Interest: The authors declare no conflict of interest.

\section{References}

1. Sweetman, S.C. Martindale 35: The Complete Drug Reference; Pharmaceutical Press: London, UK, 2007.

2. Darville, N.; Van Heerden, M.; Vynckier, A.; De Meulder, M.; Sterkens, P.; Annaert, P.; Van den Mooter, G. Intramuscular administration of paliperidone palmitate extended-release injectable microsuspension induces a subclinical inflammatory reaction modulating the pharmacokinetics in rats. J. Pharm. Sci. 2014, 103, 2072-2087. [CrossRef]

3. Wang, L.; Wang, A.; Zhao, X.; Liu, X.; Wang, D.; Sun, F.; Li, Y. Design of a long-term antipsychotic in situ forming implant and its release control method and mechanism. Int. J. Pharm. 2012, 427, 284-292. [CrossRef]

4. Nanaki, S.; Tseklima, M.; Terzopoulou, Z.; Nerantzaki, M.; Giliopoulos, D.J.; Triantafyllidis, K.; Bikiaris, D.N. Use of mesoporous cellular foam (MCF) in preparation of polymeric microspheres for long acting injectable release formulations of paliperidone antipsychotic drug. Eur. J. Pharm. Biopharm. 2017, 117, 77-90. [CrossRef] [PubMed]

5. Zhang, Q.Z.; Zha, L.S.; Zhang, Y.; Jiang, W.M.; Lu, W.; Shi, Z.Q.; Fu, S.K. The brain targeting efficiency following nasally applied MPEG-PLA nanoparticles in rats. J. Drug Target. 2006, 14, 281-290. [CrossRef] [PubMed]

6. Wissing, S.A.; Kayser, O.; Müller, R.H. Solid lipid nanoparticles for parenteral drug delivery. Adv. Drug Deliv. Rev. 2004, 56, 1257-1272. [CrossRef] [PubMed]

7. Maitra, A.; Feldmann, G.; Bisht, S. Water-Dispersible Oral, Parenteral, and Topical Formulations for Poorly Water Soluble Drugs Using Smart Polymeric Nanoparticles. U.S. Patent 8,715,741, 6 May 2014.

8. Gajra, B.; Dalwadi, C.; Patel, R. Formulation and optimization of itraconazole polymeric lipid hybrid nanoparticles (Lipomer) using box behnken design. DARU J. Pharm. Sci. 2015, 23, 3. [CrossRef]

9. Kumari, A.; Yadav, S.K.; Yadav, S.C. Biodegradable polymeric nanoparticles based drug delivery systems. Colloids Surf. B Biointerfaces 2010, 75, 1-18. [CrossRef]

10. Tavares, M.R.; De Menezes, L.R.; Do Nascimento, D.F.; Souza, D.H.S.; Reynaud, F.; Marques, M.F.V.; Tavares, M.I.B. Polymeric nanoparticles assembled with microfluidics for drug delivery across the blood-brain barrier. Eur. Phys. J. Spec. Top. 2016, 225, 779-795. [CrossRef]

11. Li, Y.; Wong, H.L.; Shuhendler, A.J.; Rauth, A.M.; Wu, X.Y. Molecular interactions, internal structure and drug release kinetics of rationally developed polymer-lipid hybrid nanoparticles. J. Control. Release 2008, 128, 60-70. [CrossRef]

12. Bhavsar, M.D.; Amiji, M.M. Development of novel biodegradable polymeric nanoparticles-in-microsphere formulation for local plasmid DNA delivery in the gastrointestinal tract. Aaps Pharmscitech 2008, 9, 288-294. [CrossRef] 
13. Marcano, R.G.d.J.V.; Tominaga, T.T.; Khalil, N.M.; Pedroso, L.S.; Mainardes, R.M. Chitosan functionalized poly ( $\varepsilon$-caprolactone) nanoparticles for amphotericin B delivery. Carbohydr. Polym. 2018, 202, 345-354. [CrossRef] [PubMed]

14. Bragta, P.; Sidhu, R.K.; Jyoti, K.; Baldi, A.; Jain, U.K.; Chandra, R.; Madan, J. Intratumoral administration of carboplatin bearing poly ( $\varepsilon$-caprolactone) nanoparticles amalgamated with in situ gel tendered augmented drug delivery, cytotoxicity, and apoptosis in melanoma tumor. Colloids Surf. B Biointerfaces 2018, 166, 339-348. [CrossRef] [PubMed]

15. Abriata, J.P.; Eloy, J.O.; Riul, T.B.; Campos, P.M.; Baruffi, M.D.; Marchetti, J.M. Poly-epsilon-caprolactone nanoparticles enhance ursolic acid in vivo efficacy against Trypanosoma cruzi infection. Mater. Sci. Eng. C 2017, 77, 1196-1203. [CrossRef]

16. Tavares, M.I.B. Development of Polycaprolactone/Poly (Vinyl Alcohol)/Clay Microparticles by Spray Drying. Mater. Sci. Appl. 2016, 7, 575-592.

17. Fessi, H.; Puisieux, F.; Devissaguet, J.P.; Ammoury, N.; Benita, S. Nanocapsule formation by interfacial polymer deposition following solvent displacement. Int. J. Pharm. 1989, 55, R1-R4. [CrossRef]

18. Kim, C.-E.; Lim, S.-K.; Kim, J.-S. In vivo antitumor effect of cromolyn in PEGylated liposomes for pancreatic cancer. J. Control. Release 2012, 157, 190-195. [CrossRef]

19. Elmowafy, M.; Viitala, T.; Ibrahim, H.M.; Abu-Elyazid, S.K.; Samy, A.; Kassem, A.; Yliperttula, M. Silymarin loaded liposomes for hepatic targeting: In vitro evaluation and HepG2 drug uptake. Eur. J. Pharm. Sci. 2013, 50, 161-171. [CrossRef]

20. Karanam, V.; Marslin, G.; Krishnamoorthy, B.; Chellan, V.; Siram, K.; Natarajan, T.; Franklin, G. Poly ( $\epsilon$-caprolactone) nanoparticles of carboplatin: Preparation, characterization and in vitro cytotoxicity evaluation in U-87 MG cell lines. Colloids Surf. B Biointerfaces 2015, 130, 48-52. [CrossRef]

21. Freiberg, S.; Zhu, X.X. Polymer microspheres for controlled drug release. Int. J. Pharm. 2004, 282, 1-18. [CrossRef]

22. Mainardes, R.M.; Evangelista, R.C. PLGA nanoparticles containing praziquantel: Effect of formulation variables on size distribution. Int. J. Pharm. 2005, 290, 137-144. [CrossRef]

23. Snehalatha, M.; Venugopal, K.; Saha, R.N. Etoposide-loaded PLGA and PCL nanoparticles I: Preparation and effect of formulation variables. Drug Deliv. 2008, 15, 267-275. [CrossRef]

24. Mora-Huertas, C.E.; Fessi, H.; Elaissari, A. Polymer-based nanocapsules for drug delivery. Int. J. Pharm. 2010, 385, 113-142. [CrossRef] [PubMed]

25. Gratieri, T.; Gelfuso, G.M.; de Freitas, O.; Rocha, E.M.; Lopez, R.F.V. Enhancing and sustaining the topical ocular delivery of fluconazole using chitosan solution and poloxamer/chitosan in situ forming gel. Eur. J. Pharm. Biopharm. 2011, 79, 320-327. [CrossRef] [PubMed]

26. Pepić, I.; Filipović-Grčić, J.; Jalšenjak, I. Bulk properties of nonionic surfactant and chitosan mixtures. Colloids Surf. A Physicochem. Eng. Asp. 2009, 336, 135-141. [CrossRef]

27. Nanaki, S.; Tseklima, M.; Christodoulou, E.; Triantafyllidis, K.; Kostoglou, M.; Bikiaris, D.N. Thiolated chitosan masked polymeric microspheres with incorporated mesocellular silica foam (MCF) for intranasal delivery of paliperidone. Polymers 2017, 9, 617. [CrossRef]

28. Xin, H.; Chen, L.; Gu, J.; Ren, X.; Luo, J.; Chen, Y.; Fang, X. Enhanced anti-glioblastoma efficacy by PTX-loaded PEGylated poly ( $\epsilon$-caprolactone) nanoparticles: In vitro and in vivo evaluation. Int. J. Pharm. 2010, 402, 238-247. [CrossRef]

29. Tavares, M.R.; de Menezes, L.R.; Dutra Filho, J.C.; Cabral, L.M.; Tavares, M.I.B. Surface-coated polycaprolactone nanoparticles with pharmaceutical application: Structural and molecular mobility evaluation by TD-NMR. Polym. Test. 2017, 60,39-48. [CrossRef]

30. Sherje, A.P.; Londhe, V. Ternary inclusion complex of paliperidone with $\beta$-cyclodextrin and hydrophilic polymer for solubility and dissolution enhancement. J. Pharm. Innov. 2015, 10, 324-334. [CrossRef]

31. Elzubair, A.; Elias, C.N.; Suarez, J.C.M.; Lopes, H.P.; Vieira, M.V.B. The physical characterization of a thermoplastic polymer for endodontic obturation. J. Dent. 2006, 34, 784-789. [CrossRef]

32. Vu-Quang, H.; Vinding, M.S.; Xia, D.; Nielsen, T.; Ullisch, M.G.; Dong, M.; Kjems, J. Chitosan-coated poly (lactic-co-glycolic acid) perfluorooctyl bromide nanoparticles for cell labeling in 19F magnetic resonance imaging. Carbohydr. Polym. 2016, 136, 936-944. [CrossRef]

33. Misra, R.; Acharya, S.; Dilnawaz, F.; Sahoo, S.K. Sustained antibacterial activity of doxycycline-loaded poly (D,L-lactide-co-glycolide) and poly ( $\varepsilon$-caprolactone) nanoparticles. Nanomedicine 2009, 4, 519-530. [CrossRef] 
34. Ding, H.; Ma, Y. Computer simulation of the role of protein corona in cellular delivery of nanoparticles. Biomaterials 2014, 35, 8703-8710. [CrossRef] [PubMed]

35. Hoven, V.P.; Tangpasuthadol, V.; Angkitpaiboon, Y.; Vallapa, N.; Kiatkamjornwong, S. Surface-charged chitosan: Preparation and protein adsorption. Carbohydr. Polym. 2007, 68, 44-53. [CrossRef]

36. Müller, L.; Müller, F.A. Preparation of SBF with different HCO3-content and its influence on the composition of biomimetic apatites. Acta Biomater. 2006, 2, 181-189. [CrossRef] [PubMed]

37. Deligianni, D.D.; Katsala, N.; Ladas, S.; Sotiropoulou, D.; Amedee, J.; Missirlis, Y.F. Effect of surface roughness of the titanium alloy $\mathrm{Ti}-6 \mathrm{Al}-4 \mathrm{~V}$ on human bone marrow cell response and on protein adsorption. Biomaterials 2001, 22, 1241-1251. [CrossRef]

38. Milani, S.; Baldelli Bombelli, F.; Pitek, A.S.; Dawson, K.A.; Radler, J. Reversible versus irreversible binding of transferrin to polystyrene nanoparticles: Soft and hard corona. ACS Nano 2012, 6, 2532-2541. [CrossRef]

39. Xiao, W.; Xiong, J.; Zhang, S.; Xiong, Y.; Zhang, H.; Gao, H. Influence of ligands property and particle size of gold nanoparticles on the protein adsorption and corresponding targeting ability. Int. J. Pharm. 2018, 538, 105-111. [CrossRef]

40. Tilley, A.J.; Drummond, C.J.; Boyd, B.J. Disposition and association of the steric stabilizer Pluronic®F127 in lyotropic liquid crystalline nanostructured particle dispersions. J. Colloid Interface Sci. 2013, 392, 288-296. [CrossRef]

41. Kuo, J.S. Effect of Pluronic-block copolymers on the reduction of serum-mediated inhibition of gene transfer of polyethyleneimine-DNA complexes. Biotechnol. Appl. Biochem. 2003, 37, 267-271. [CrossRef]

42. Prata, A.S.; Grosso, C.R.F. Production of microparticles with gelatin and chitosan. Carbohydr. Polym. 2015, 116, 292-299. [CrossRef]

43. Kim, U.-J.; Kuga, S. Ion-exchange separation of proteins by polyallylamine-grafted cellulose gel. J. Chromatogr. A 2002, 955, 191-196. [CrossRef]

44. Sukanya, V.S.; Mohanan, P.V. Degradation of Poly ( $\varepsilon$-caprolactone) and bio-interactions with mouse bone marrow mesenchymal stem cells. Colloids Surf. B Biointerfaces 2018, 163, 107-118.

45. Grabowski, N.; Hillaireau, H.; Vergnaud, J.; Tsapis, N.; Pallardy, M.; Kerdine-Römer, S.; Fattal, E. Surface coating mediates the toxicity of polymeric nanoparticles towards human-like macrophages. Int. J. Pharm. 2015, 482, 75-83. [CrossRef] [PubMed]

46. Richardson, S.W.; Kolbe, H.J.; Duncan, R. Potential of low molecular mass chitosan as a DNA delivery system: Biocompatibility, body distribution and ability to complex and protect DNA. Int. J. Pharm. 1999, 178, 231-243. [CrossRef]

47. Nafee, N.; Schneider, M.; Schaefer, U.F.; Lehr, C.-M. Relevance of the colloidal stability of chitosan/PLGA nanoparticles on their cytotoxicity profile. Int. J. Pharm. 2009, 381, 130-139. [CrossRef] [PubMed]

48. Schöler, N.; Hahn, H.; Müller, R.H.; Liesenfeld, O. Effect of lipid matrix and size of solid lipid nanoparticles (SLN) on the viability and cytokine production of macrophages. Int. J. Pharm. 2002, 231, 167-176. [CrossRef]

49. Halliwell, B.; Gutteridge, J.M.C. Free Radicals in Biology and Medicine; Oxford University Press: New York, NY, USA, 2015.

(C) 2020 by the authors. Licensee MDPI, Basel, Switzerland. This article is an open access article distributed under the terms and conditions of the Creative Commons Attribution (CC BY) license (http://creativecommons.org/licenses/by/4.0/). 